\title{
Salt Stress Restraining Genotypes of Mungbean (Vigna radiata L. Wilczek): Gateway for Genetic Amelioration
}

\author{
Manoj Katiyar ${ }^{1 *}$, D. K. Srivastava ${ }^{2}$, Ravindra Tomar $^{1}$, Rahul Kumar $^{1}$ and S. D. Nitesh ${ }^{3}$ \\ ${ }^{1}$ Chandra Shekhar Azad University of Agriculture and Technology, Kanpur, U.P., India \\ ${ }^{2}$ Joint Director, Council of Science and Technology, Lucknow, U.P., India \\ ${ }^{3}$ Department of Genetics and Plant Breeding, Chandra Shekhar Azad University of \\ Agriculture and Technology, Kanpur, U.P., India
}

*Corresponding author

\section{A B S T R A C T}

\section{Keywords}

Salt stress, ESP, Mungbean

\section{Article Info}

Accepted:

10 November 2019

Available Online:

10 December 2019
Thirty genotypes of mungbean (Vigna radiata L. Wilczek) of diverse genetic origin were screened for salt tolerance with ESP levels of 20,30 and 40 along with control in earthen pots during summer, 2018 in Completely Randomized Design (CRD) with 3 replications. The observations were recorded for grain yield and its contributing traits number of pods/plant, pod length, number of seeds/pod and 100 -seed weight. The investigated genotypes exhibited significantly variable response towards salt stress. Salt stress along with high-temperature stress-induced osmotic stress severely limiting the yield contributing traits. Genotypes KM 2241, IPM 02-3, Pusa Vishal and EC 88 maintained superiorly at all the levels of ESP for almost all the traits and there was marginal reduction with progressively increasing level of ESP indicated their efficient adaptability under salt stress environment and can be considered as salt tolerant. Genotypes SML 668, Jalgaon, I-51, IPM 99-125 and I10 showed resistance/tolerance with respect to all the traits up to 30 ESP. The above-said genotypes seem to have better resistance/tolerance to salt stress and can be used as source of resistant genes which can be introgressed in salt-sensitive mungbean genotypes through breeding.

\section{Introduction}

Mungbean is the important short duration pulse crop which is cultivated across seasons, cropping situations and a wide range of climatic zones of India. The stagnant yield of this crop for several decades has been largely accounted to its susceptibility to various biotic and abiotic stresses at different growth stages of the crop. Among the abiotic stresses, salinity stress is more atrocious limiting growth and grain yield worldwide. Due to natural salinity and human inheritances, the arable land is continuously transforming into 
saline that is excepted to have overwhelming global effects, resulting in up to $50 \%$ land loss by 2050 (Saha et al., 2010; Hasanuzzaman et al., 2013). Evaluation of crop plants in saline environment will certainly provide suitable material as a source of genes that can be introgressed in salt-sensitive genotypes through breeding (Nair et al., 2012). The understanding of salt stresses, however, still remarks incomplete because of the complexity of the process presenting an ionic component on the one hand and an osmotic component on the other, which involves morphological, physiological and metabolic change. These changes permit the plant to restore conditions, permitting continued growth under salinity stress.

A number of mechanisms contribute to salt tolerance; commonly proposed mechanism includes compartmentation of ions in vacuoles, accumulations of components solutes in the cytoplasm as well as genetic salt resistance. Due to complex nature f salinity stress, little progress has been made in developing salt tolerance mungbean varieties (Singh and Singh, 2011).

Keeping in view the above aspects, the present study aimed to identify the most salt-tolerant genotypes of mungbean that can be used as parents to introduce genes providing salt tolerance in mungbean through breeding.

\section{Materials and Methods}

The experimental material comprised 30 genotypes of mungbean (Vigna radiata L. Wilczek). These genotypes have a different geographic origin (Table 1). Selection of genotypes was made based on available information regarding their performance under stress conditions. Some are the released cultivars and other is the germplasm accessions, with indigenous as well as exotic origin. Three varieties which are recommended for cultivation in U.P. and are popular among the farmers (viz. KM 2241, IPM 02-3 and Pant M 8) and 27 other genotypes were taken. All thirty genotypes comprised experimental material for this experiment.

Earthen pots (10 kg capacity) were filled with soils having ESP level of 20, 30, 40 and 50 along with one control pot with normal soil. The experiment was conducted in Completely Randomized Design (CRD) with 3 replications at soil salinity research station, Dileep Nagar, Kanpur, during summer 2018. Before sowing an equal amount of water was added in each pot in order to have sufficient moisture for germination of seeds. Rhizobium treated five seeds of each genotype in each pot were sown at equal distance. After 15 days of sowing, thinning was done leaving only three plants in each pot. Removal of weeds was done by hand and scheduled irrigation practice was maintained manually at regular time intervals for crop season. Observations were recorded for grain yield/plant (g) and its contributing traits viz. number of pods/plant, pod length $(\mathrm{cm})$, number of seeds/pod and 100 -seed weight $(\mathrm{g})$ at maturity time and averaged for 3 replications. The analysis of variance was applied to determine the significance of differences among the treatments and genotypes.

\section{Results and Discussion}

At 50ESP, the seeds did germinate but the seedlings did not survive after a few days of germination.

The number of pods per plant varied from 13.4 to 29.2 among the genotypes in control treatment (Fig. 1). As the sodicity level increased, there was reduction in number of pods/plant in all the genotypes. At 40 ESP there was substantial reduction in pods/plant as compared to control. However, in 
genotypes I 51, IPM 99-125, Jalgaon, I 10 and SML 668 there was comparatively less reduction in pod number as compared to other genotypes up to 30 ESP. Genotypes KM 2241, IPM 2-3, Pusa Vishal and EC 88 almost maintained their character up to 40 ESP. Similar results have also been reported by Seharwat et al., 2015 in mungbean.

With increased ESP level from control to 40 ESP, there was a reduction in pod length (Fig. 5). In some cases it was substantial while in others it was negligible. EC 88, IPM 2-3, KM 2241 and Pusa Vishal were least affected even up to 40 ESP showing thereby that these genotypes have better tolerance to sodicity (Fig. 2 and 3). SML 668, Jalgaon, IPM 99125, I 51 and I 10 almost maintained their pod length up to $30 \mathrm{ESP}$. Similar results have also been reported by Ahmed (2009), Sunil et al., (2012), Sehrawat et al., (2013 c, d).

The 100 seed weight varied from $2.4 \mathrm{~g}$ to $4.2 \mathrm{~g}$ among the genotypes tested in the control treatment (Fig. 7). With the increase level of ESP from control to $40 \mathrm{ESP}$, there had been progressive decrease in seed size. At 40 ESP, there was substantial decrease in all the genotypes except KM 2241, EC 88, IPM 2-3 and Pusa Vishal, where there was comparatively less reduction, exhibiting thereby better tolerance to sodicity. Genotypes IPM 99-125, Jalgaon, SML 668, I-51 and I-10 maintained seed weight up to $30 \mathrm{ESP}$, after that there was a substantial reduction in seed size.

Yield per plant which is resultant of a number of pods, pod length, seeds per pod and 100seed weight also showed similar trend. As the ESP level progressed, there had been reduction in yield per plant in all the genotypes (Fig. 6). The reduction was substantial at 40 ESP as compared to 20 ESP. Some genotypes maintained the yield level up to $30 \mathrm{ESP}$ with minor reduction. Genotypes like IPM 2-3, Pusa Vishal, KM 2241, EC 88 showed almost consistent performance at all ESP levels depicting that these genotypes have better tolerance to sodicity (Fig. 4). Reduced yield in mungbean under salt stress may be due to more flower shedding and reduced photosynthetic efficiency to fill the developing seeds.

Salt induced desiccation resulted in more flower shedding and pod shattering during summer which further adversely affected the texture and quality of seed. Reduced yield in mungbean under salt stress may be due to more flowers shedding, reduced photosynthetic efficiency per day of the plant to fill the developing seeds and shattering of pods (Ahmed, 2009, Sunil et al., 2012). The other expected causes of the reduction in yield per plant yield components could be the shrinkage of the cell contents reduced development and differentiation of tissues, imbalanced nutrition, damage of membrane and disturbed avoidance mechanism. Severe reduction in yield attributes due to salt stress showed similarities with earlier finding in mungbean (Sehrawat et al., $2013 \mathrm{c}, \mathrm{d}$ ).

The investigated mungbean genotypes showed considerable differences for all the measured traits in response to salt stress. Salt stress along with high-temperature stress and salinity induced osmotic stress severely limited the plant growth and yield characteristics during summer. The adverse effect of salinity on growth and metabolism may be due to cosmetic inhibition of water availability (dehydration), toxic effect of high salt ions and disturbance of the uptake and translocation ions in saline salt, creates high ionic imbalances that may impair the salinity of root membrane. Genotypes KM 2241, IPM 02-3, Pusa Vishal and EC 88 maintained their superiority at all the level of ESP for almost all the traits and there was marginal reduction with progressively increasing level of ESP. 
Table.1 Genotypes with their geographic origin/source taken for study

\begin{tabular}{|c|c|c|c|c|c|}
\hline $\begin{array}{l}\text { Sl. } \\
\text { No. }\end{array}$ & Genotype & $\begin{array}{c}\text { Geographic origin } \\
\text { /source }\end{array}$ & $\begin{array}{l}\text { Sl. } \\
\text { No. }\end{array}$ & Genotype & $\begin{array}{c}\text { Geographic } \\
\text { origin /source }\end{array}$ \\
\hline 1. & $\begin{array}{c}\text { Pusa } \\
\text { Vishal }\end{array}$ & IARI, New Delhi & 16. & I-55 & IIPR, Kanpur \\
\hline 2. & VBG-2 & NPRC, Vamban & 17. & SML 668 & PAU, Ludhiana \\
\hline 3. & MH 2-15 & HAU, Hisar & 18. & I-62 & IIPR, Kanpur \\
\hline 4. & $\begin{array}{l}\text { IPM 99- } \\
125\end{array}$ & IIPR, Kanpur & 19. & Kopergaon & Maharashtra \\
\hline 5. & TARM 2 & BARC, Akola & 20. & BM-4 & ARS, Badnapur \\
\hline 6 & Shalimar 2 & SKUA\&T, Srinagar & 21. & Phule M-2 & MPKVV, Rahuri \\
\hline 7 & PUSA 9531 & IARI, New Delhi & 22. & I-51 & IIPR, Kanpur \\
\hline 8. & I-58 & IIPR, Kanpur & 23. & I 50-7 & IIPR, Kanpur \\
\hline 9. & LGG 420 & APAU, Lam & 24. & IPM 205-7 & IIPR, Kanpur \\
\hline 10. & Jalgaon & Maharashtra & 25. & EC-88 & $\begin{array}{l}\text { NBPGR, New } \\
\text { Delhi }\end{array}$ \\
\hline 11. & SML 134 & PAU, Ludhiana & 26. & I-10 & IIPR, Kanpur \\
\hline 12. & I-60 & IIPR, Kanpur & 27. & IPM 2-3 & IIPR, Kanpur \\
\hline 13. & IPM 2-14 & IIPR, Kanpur & 28. & Pant M-8 & $\begin{array}{l}\text { GBPUA\&T, } \\
\text { Pantnagar }\end{array}$ \\
\hline 14. & HUM 1 & BHU, Varanasi & 29. & KM 2241 & $\begin{array}{l}\text { CSAUA\&T, } \\
\text { Kanpur }\end{array}$ \\
\hline 15. & PDM 139 & IIPR, Kanpur & 30. & I-59 & IIPR, Kanpur \\
\hline
\end{tabular}

Fig.1

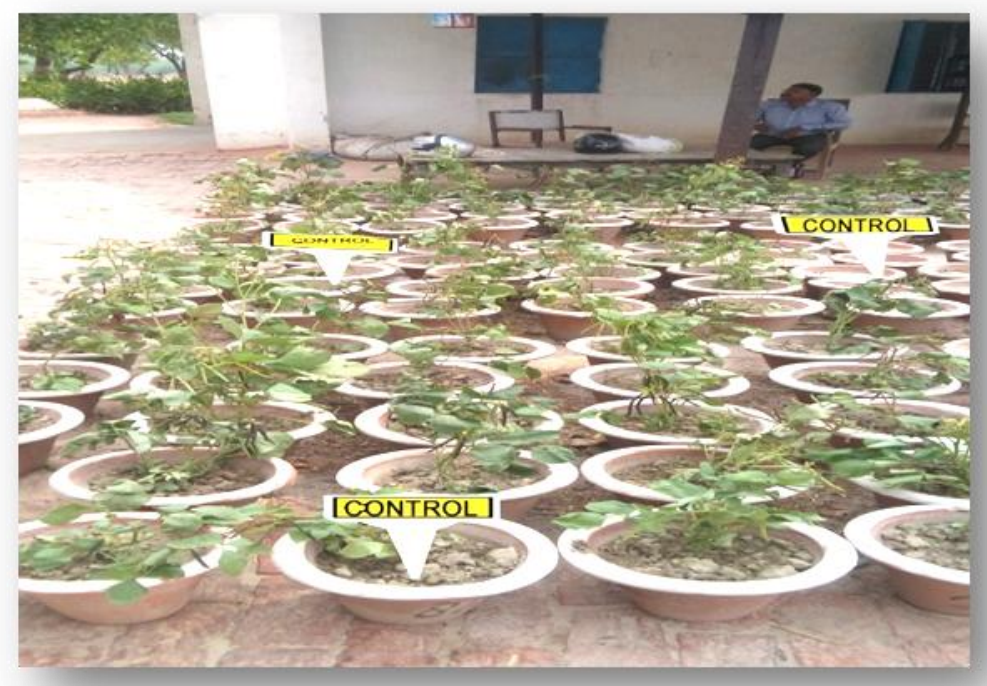


Fig.2 Different genotypes of mungbean superior at all levels of ESP
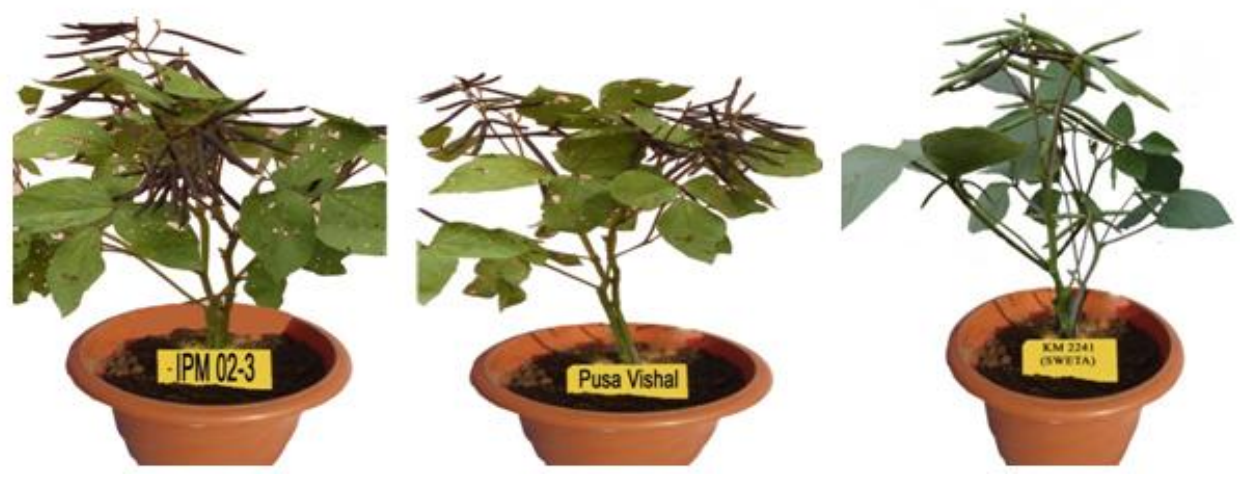

Fig.3 Different genotypes of mungbean superior at 30 ESP
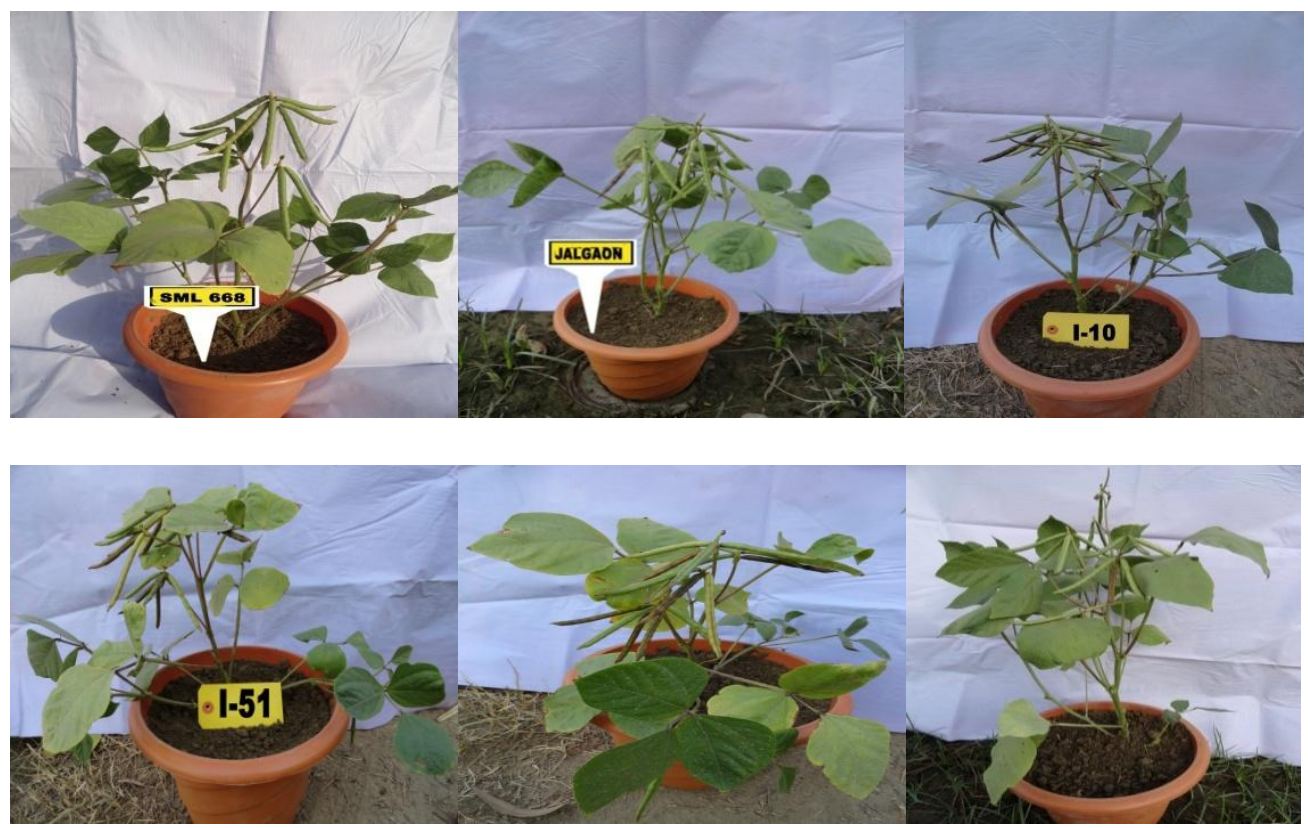
Fig.4 Number of pods per plant at different Sodicity levels

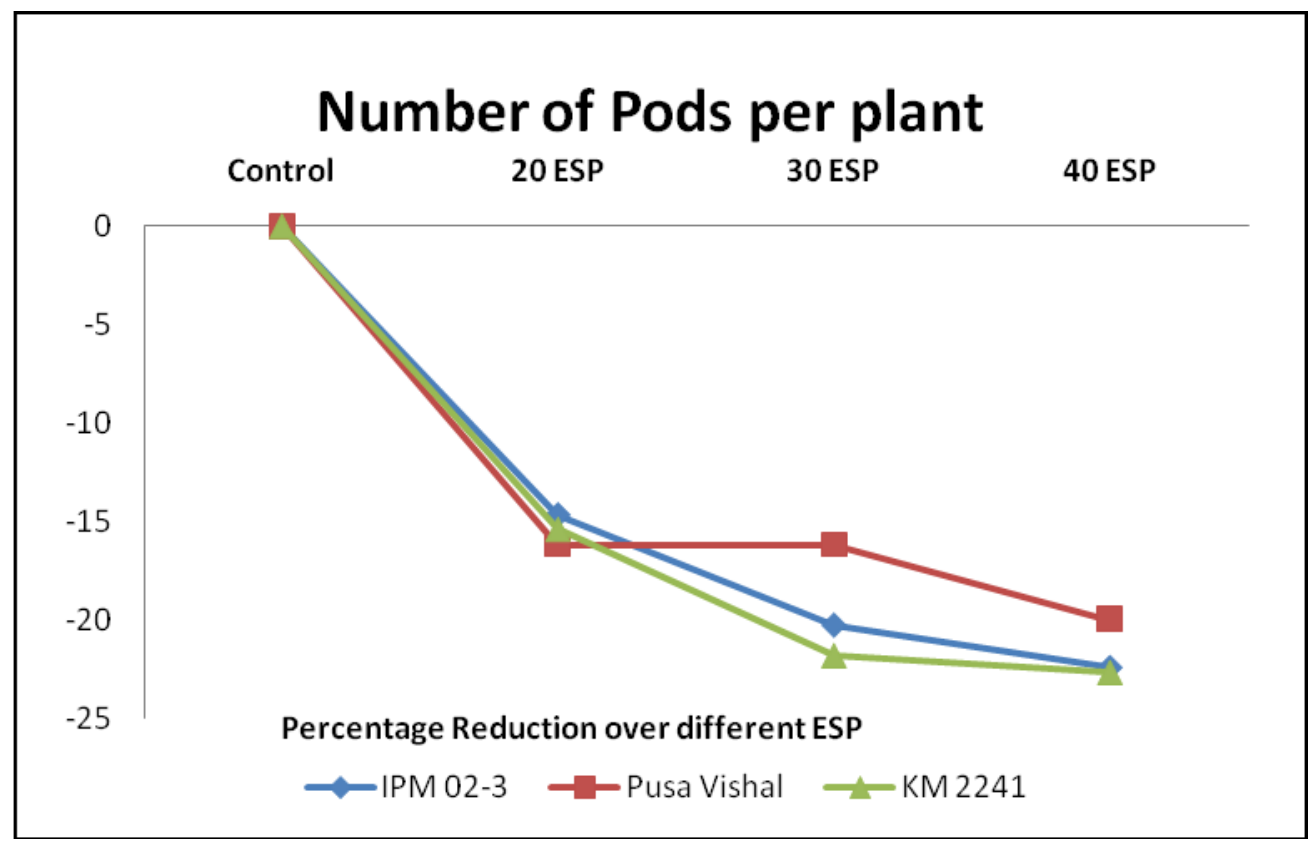

Fig.5 Effect of different ESP levels on pod length

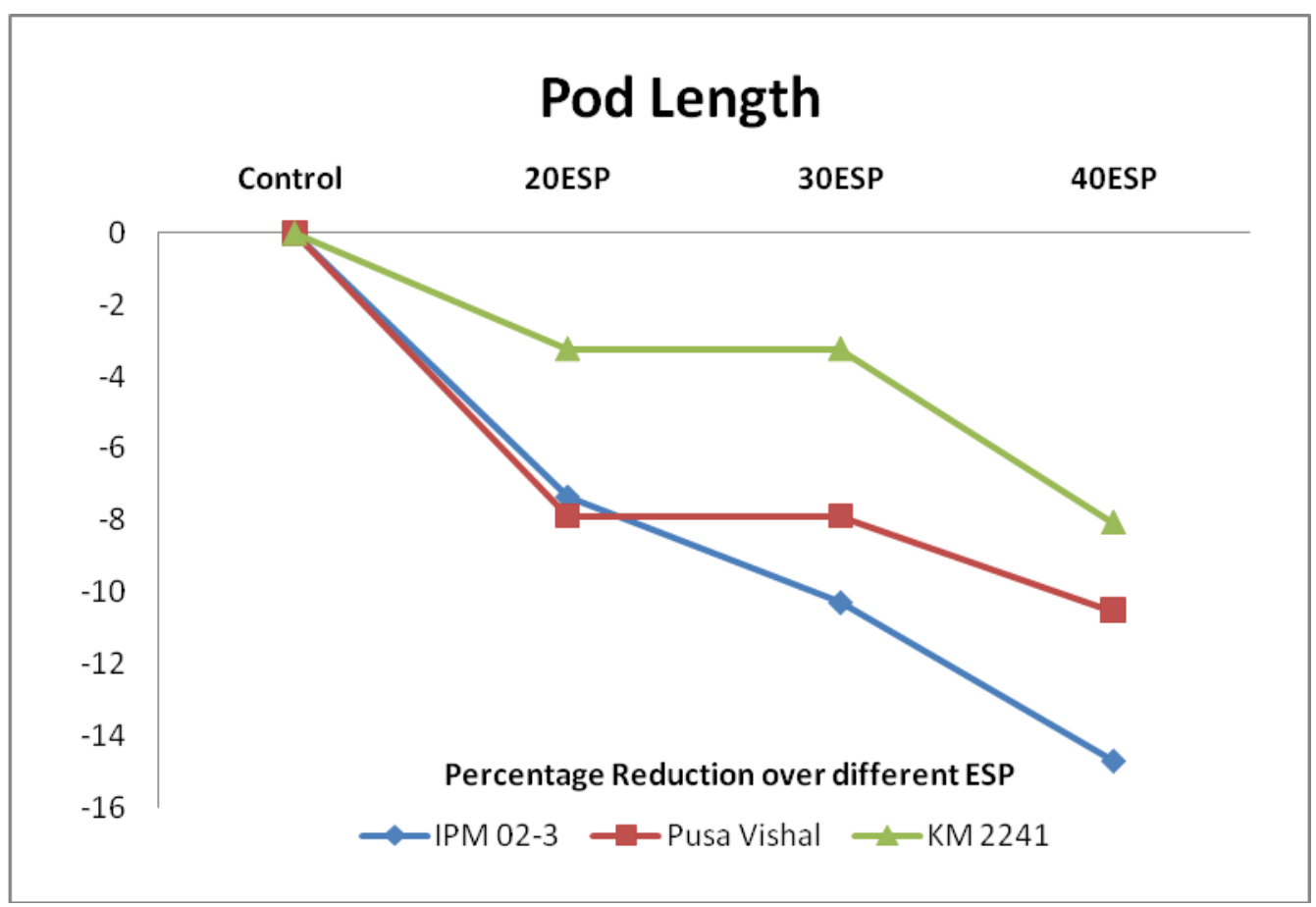


Fig.6 Yield per plant of mungbean genotypes at different ESP levels

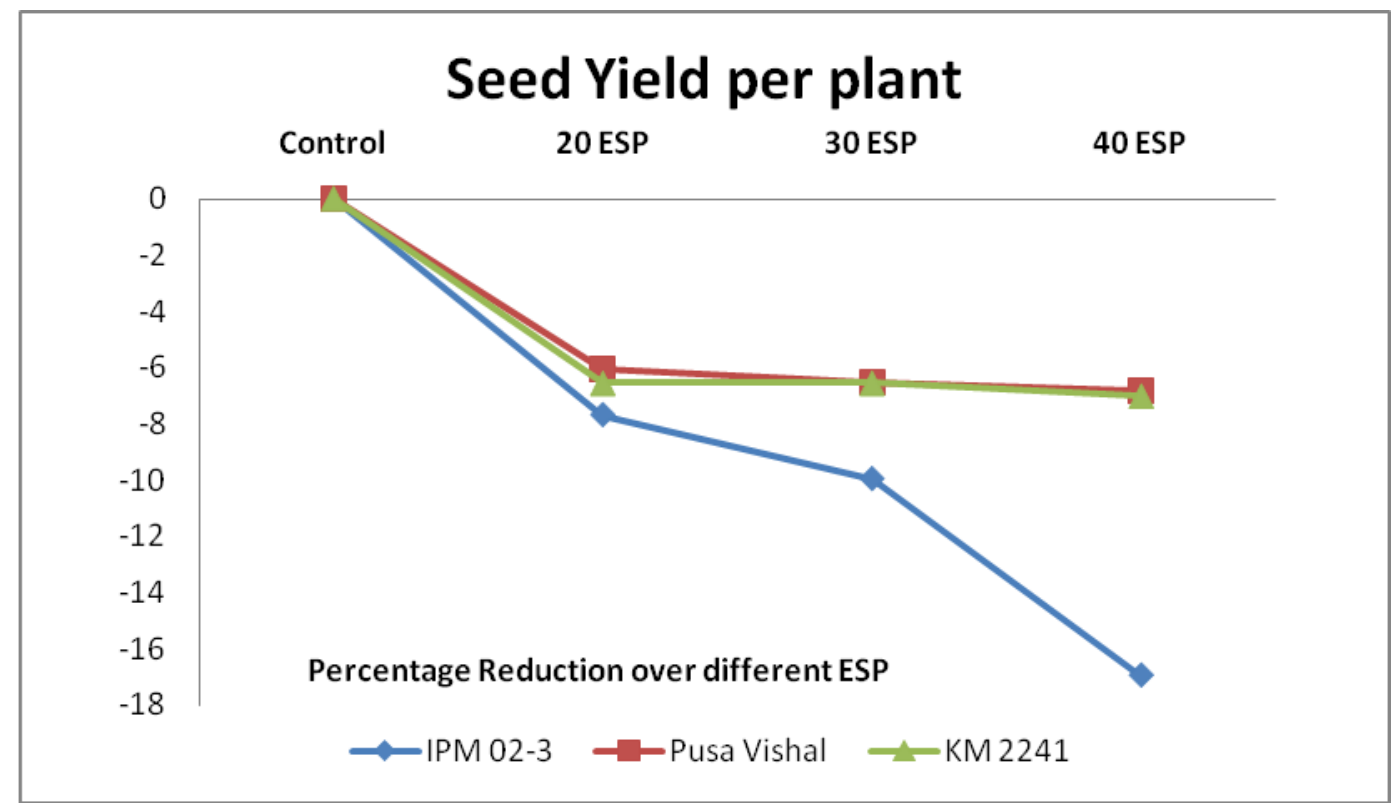

Fig.7 100-seed weight of different genotypes at different ESP levels

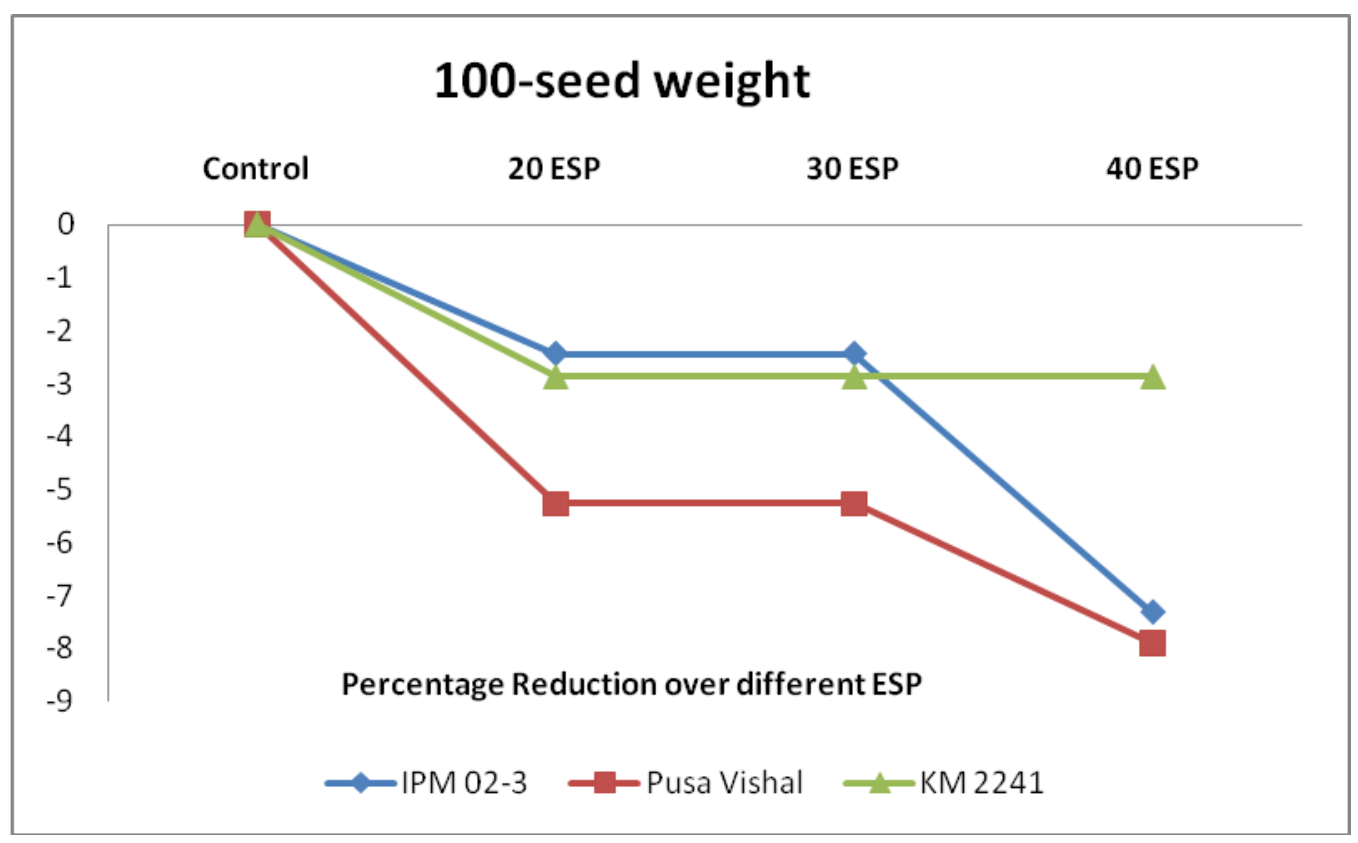


Genotypes SML 668, Jalgaon, I-51, IPM 99125 and I-10 showed resistance/tolerance with respect to all the traits up to $30 \mathrm{ESP}$. These genotypes seem to have better resistance/tolerance to salt stress and can be used in resistant genes which can be introgressed in all the salt-sensitive mungbean genotypes through breeding for developing mungbean cultivars possessing resistance/tolerance to sodic conditions.

\section{Acknowledgement}

The first author gratefully acknowledges the financial support provided by Director, Council of Science and Technology, U.P., Lucknow for carrying out the research work.

\section{References}

Ahmed S. 2009. Effect of soil salinity on the yield and yield components of mungbean. Pak. J. Bot. 41:263-268

Hasnuzzaman, M. Nathan, K, Fujita, M. 2013. Plant response to salt stress and the role of exogenous protectants to mitigate salt-induced damages. In: Ahmad, P., Azoom, M.M, Prasad, M.N.V. (Eds), Ecophysiology and responses of plants under salt stress. Springer, New York, pp. 25-87.

Nair, R.M., Schafleimer, R., Kenyon, L. Srinivasan, R., Easdown, W., Ebert, R.W., Hanson, P. 2012. Genetic improvements of mungbean SABRAO J. Breed. Genet. 44: 177-190

Saha, P., Chatterjee, P., Biswas, A.K. 210. $\mathrm{NaCl}$ pretreatment alleviates salt stress by enhancement of defense and osmolyte accumulation in mungbean Indian J. Exp. Bio. 48: 593-600

Sehrawat, N, Bhat, K.V., Sairam, R.K. Jaiswal, P.K. 2013d. Identification of salt-resistant wild relatives of mungbean. Asia J. Plant Sci Res. 3: 41-49

Sehrawat, N., Bhat, K.V., SaiRam, R.K., Tomooka, N., Kaga, A., Shu, V., Jaiswal, P.K. 2013 c. Diversity analysis and confirmation of intraspecific hybrids for salt tolerance in mungbean. Int. J. Integ Biol. 16: 6573.

Sehrawat, N., Yadav, M., Kangila, V. Bhat, Sairam, R.K. and Jaiswal, P.K. 2015. Effect of salinity stress on mungbean (Vigna radiata L. Wilczek) during consecutive summer and spring seasons. J. Agri. Sci 60: 23-32.

Singh, D.P. Singh, B.B. 2011. Breeding for tolerance to abiotic stresses in mungbean. J. Food Legumes 24: 83-90

Sunil KR, B., Prakash, M. Sathiya N., Gokulakrishnan, J. 2012. Breeding for salinity tolerance in mungbean. In 2nd Intr. Conf. on Asia Agriculture and Animal (ECAAA 2012). APCBEE Procedia Vol 4:30-35

\section{How to cite this article:}

Manoj Katiyar, D. K. Srivastava, Ravindra Tomar, Rahul Kumar and Nitesh, S. D. 2019. Salt Stress Restraining Genotypes of Mungbean (Vigna radiata L. Wilczek): Gateway for Genetic Amelioration. Int.J.Curr.Microbiol.App.Sci. 8(12): 1063-1070. doi: https://doi.org/10.20546/ijcmas.2019.812.135 